\title{
Will we have enough hygienists?
}

\author{
A survey of dental hygienist numbers in Canada, the European Economic area, Japan and the United States of \\ America in 1998 K. A. Eaton, H. N. Newman and E. Widström Br Dent J 2003; 195: 595-598
}

\section{Objective}

The aims of this study were to establish how many dental hygienists were licensed to practice in Canada, Japan, USA and the 18 member states of the European Economic Area (EEA) and to compare these with the populations and numbers of dentists practising in the countries concerned.

\section{Method}

Data for the overall populations, numbers of 'active' dentists, of dental hygienists and of employed dental hygienists in the member states of the EEA in 1998 were taken from the responses to a Council of European Chief Dental Officers survey carried out in 2000/2001. Data for these variables for Canada, Japan and the USA in 1998 were accessed from published reports. The ratios of population: active dentist; population: dental hygienist; and active dentist: dental hygienist were calculated and compared.

\section{Results}

The overall populations and total number of active dentists in the 18 EEA member states and Canada plus Japan plus the USA were broadly similar in 1998 (EEA overall population 381 million with 245,169 active dentists: Canada/Japan/USA overall population 421 million with 253,825 active dentists). However, there were only 13,295 dental hygienists in the EEA as opposed to a total of 215,435 in Canada, Japan and the USA. In terms of population:dental hygienist and active dentist: dental hygienist ratios the UK was found to have proportionally far fewer dental hygienists than Canada, Japan, USA or the four Nordic members of the EEA.

\section{Conclusion}

The survey revealed that relative to overall populations and numbers of dentists, there are far fewer dental hygienists in the EEA than in Canada, Japan and the USA and that scope for the UK to import dental hygienists from other EEA member states is probably very limited.

\section{IN BRIEF}

- This paper reports a survey of dental hygienist numbers in Canada, Japan, the USA and Western Europe.

- The results indicate that although the combined populations of Canada, Japan and the USA and the total number of dentists working in these three countries are broadly similar to those in the 18 member states of the European Economic Area (EEA), there are over 15 times as many dental hygienists in the three countries than in the EEA.

- Fewer than 10,000 dental hygienists worked in EEA member states other than the UK.

- The potential for the UK to recruit large numbers of hygienists from the EEA is therefore extremely poor.

\section{COMMENT}

Determining the number of workers required in the future has always been a complicated and inexact science. However, the move in the last decade toward a team based approach to the delivery of dental care, the changing gender balance in the workforce, and the freedom of workers to move across international boundaries within the European Economic Area, have complicated matters further. Thus, any study which provides information to help in the planning process is welcome.

This investigation set out to establish the numbers of dental hygienists licensed to practice in Canada, Japan, the USA and the 18 states of the European Economic Area (EEA) and to compare these as a ratio with the overall population and with the number of active dentists. Data were collected from surveys of Chief Dental Officers in Europe and from published reports elsewhere.

The results indicate that whilst the population:dentist ratio was in the same order of magnitude for Canada, Japan, the USA and the EEA, the population:hygienist ratio and active dentist:dental hygienist ratio revealed proportionately many fewer hygienists in Europe. Large variations were observed within the European countries regarding both the population:hygienist ratio and the active dentist:hygienist ratio. Over half of all dental hygienists in Europe were employed in either Sweden or the UK. However, when population ratios were taken into account, the UK. had comparatively fewer hygienists than Iceland, the Netherlands and the four Nordic countries. The same held true for dentist:hygienist ratios. Some European states, such as Austria and France, neither trained nor employed dental hygienists. The authors report that for the UK to match the ratio of hygienists typical in Nordic countries and the non-European countries surveyed, would require increases of $300 \%$ and $700 \%$ respectively. However, the ideal population:dentist:hygienist ratios are unknown and likely to vary from state to state, but would make an interesting topic for future research in this area.

Finally, in determining the contribution of the workforce to healthcare delivery, it is the number of whole time equivalents, or sessions worked, that is of greatest importance rather than the number registered. As the authors admit, they had difficulty establishing the relationship between the number of hygienists registered and the number employed. Nevertheless, this study indicates that in planning the dental hygienist workforce of tomorrow, migration from the EEA is unlikely to be a significant factor as a means of expanding the number of dental hygienists in the UK.

\section{G. Chestnutt}

Senior Lecturer and Hon. Consultant in Dental Public Health, University of Wales College of Medicine, Cardiff doi:10.1038/sj.bdj.4810733 